\title{
Comparison Between Paracetamol Vs Voltral Suppositories For Post Operative Pain In Gynaecological Procedures
}

\section{Zeeshan Khan, ${ }^{1}$ Saadia Khaleeq, ${ }^{2}$ Abaid ur Rehman, ${ }^{3}$ Aasam Maan, ${ }^{4}$ Umer Farooq, ${ }^{5}$ Amjad Nadeem ${ }^{6}$}

\begin{abstract}
Objective: To compare intravenous paracetamol vs Voltral (Diclofenac) suppositories for post operative pain in gynaecological procedures.

Methods: This was a non randomized controlled trial that was carried out at Department of Anaesthesiology, Sheikh Zayed Hospital, Rahim Yar Khan during 01-07-2019 to 31-12-2019 in which all female cases with age range of 20 to 60 year undergoing any gynaecological surgery requiring general anaesthesia were included. The cases were divided into two equal groups and anesthesia was offered in standard doses. Just before reversal the cases in group A were given intravenous paracetamol in a dose of $1 \mathrm{gm}$ stat and then at 8hour interval and those in group B were offered diclofenac suppositories in a dose of $50 \mathrm{mg}$ twice a day, 12 hours apart. The pain was assessed at 4,8,12 and 24 hours and was labelled on visual analogue scale (VAS).

Results: In this study there were 62 cases (31 in each group). The mean age in group A and B was $45.41 \pm 10.21$ vs $48.12 \pm 11.13$ years with $p=0.47$. Mean duration of surgery in both groups was $57.51 \pm 15.23$ vs53.11 \pm 14.79 minutes with $p=0.81$. There was no significant difference in mean pain score at 4 and 8 hours with $p=0.91$ and 0.81 respectively in group $A$ and $B$. Mean pain score was $4.43 \pm 1.67$ vs $3.21 \pm 1.09$ with $p=$ 0.01 at 12 and $4.57 \pm 1.71$ vs $3.34 \pm 1.27$ at 24 hours in group $A$ and $B$ with p values of 0.01 each. Mean time taken for rescue analgesia was $9.13 \pm 2.11$ in group $A$ and $13.11 \pm 1.23$ hours in group B with $p=0.001$.

Conclusion; Voltral (Diclofenac sodium) suppositories are better than paracetamol infusion in controlling pain after gynecological surgeries and this difference is significantly better at 12 and 24 hours.

Key words: Gynaecological surgery, Pain, Paracetamol, Voltral suppository

How to cite: Khan Z., Khaleeq S., Rehman Ur A., Maan A., Farooq U. Nadeem A. Comparison Between Paracetamol Vs Voltral Suppositories for Post-Operative Pain in Gynaecological Procedures. Esculapio 2021;17(02):192-195.
\end{abstract}

DOI: https://doi.org/10.51273/esc21.2517217

\section{Introduction}

$\mathrm{G}^{\mathrm{y}}$ ynaecological surgeries are one of the most commonly performed surgical interventions in collaboration of anaesthesiologist and post-operative pain is one of the major concerns that are addressed by the anaesthetists as part of post anesthesia care unit.

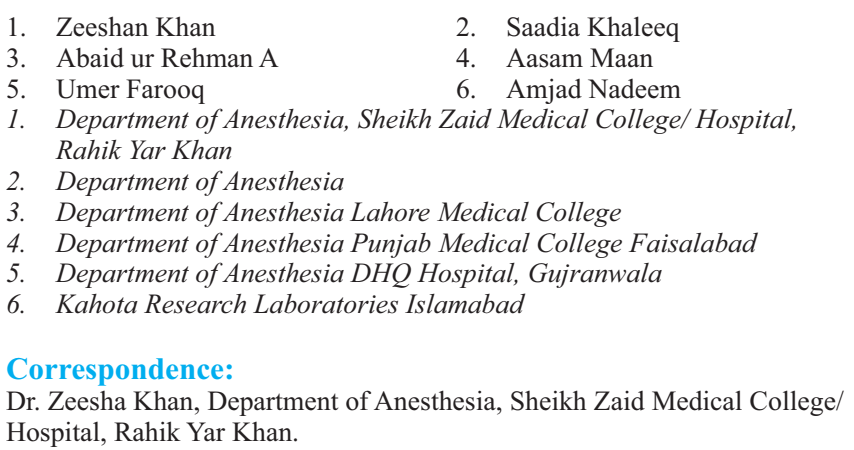

13-05-2021
It can impact greatly in terms of physiological as well as psychological responses after surgery. ${ }^{1-2}$

Acute pain may last for longer duration of time because of the local tissue damage associated with surgery and associated pathophysiological responses both in central as well as peripheral nervous systems augmenting analgesics with longer duration of action. For this particular reason the data has revealed a diversity from local to systemic analgesia and from simple to multimodal ones, all have been tried in the past with varying degree of success rates and pain still remained a point of concern. Side effect profile of the drugs, route of administration and cost of treatment are the other points of concern in selection of the drug. In resource depleted areas like ours simple and still most commonly practiced agents are diclofenac and acetaminophen. They have been used via various routes ranging from intra venous, intramuscular as well as rectal suppositories and shown promising results. ${ }^{3-4}$ 
Paracetamol is frequently used as non opioid analgesic in postoperative pain and has a morphine-sparing effect. Its mechanism of action is not fully understood, but it is generally accepted that paracetamol is a centrally acting drug. ${ }^{5-6}$ Diclofenac is of the most commonly practiced analgesic. It also has the anti-inflammatory properties and exerts its action via inhibition of prostaglandin synthesis by inhibiting cyclooxygenase-1 and cyclooxygenase- 2 with relative equipotency. Per rectal administration has shown good efficacies in post operative pain. ${ }^{7-8}$

These two drugs are widely practiced but lacked the data regarding per rectal diclofenac vs intravenous paracetamol, where the formed is very least prescribed in Pakistan. That's why this study was planned to look for better agent to decrease morbidity in such cases with choice of better agent.

\section{Methods}

This was a non randomized controlled trial that was carried out at Department of Anaesthesiology, Sheikh Zayed Hospital, Rahim Yar Khan during 01-07-2019 to 31-12-2019. The approval was taken from IRB committee with reference no 209/IRB/SZMC/SZH dated 30-06-2019 and an informed consent was taken from each subject to include in the study. The sample size was calculated by open epi calculator via non probability consecutive sampling as 62 (31 in each group) by keeping the confidence interval as $95 \%$, power equal to $80 \%$ and mean pain on VAS as $3.03 \pm$ 1.02 vs $3.8 \pm 1.13$ in Paracetamol vs Diclofenac respectively at 24 hours. ${ }^{14}$

In this study, all female cases with age range of 20 to 60 year undergoing any gynaecological surgery requiring general anaesthesia were included. These cases were divided into two equal groups by using lottery method in a ratio of 1:1. Anesthesia was offered to all cases by using injection propofol in a dose of $2 \mathrm{mg}$ per $\mathrm{kg}$, fentany ${ }^{\mathrm{l}}$ in a dose of 3 micrograms per $\mathrm{kg}$, dormicum in a dose of $0.5 \mathrm{mg}$ per $\mathrm{kg}$ and injection atracurium in a dose of $0.5 \mathrm{mg}$ per $\mathrm{kg}$. Inhalational anesthesia and reversal was given in standard doses. Vitals were monitored regularly pre anesthesia and at regular intervals during whole surgery. Just before offering the reversal drugs, the cases in group A were given intravenous paracetamol in a dose of $1 \mathrm{gm}$ stat and was continued three times a day at 8-hour interval and those in group B were offered diclofenac suppositories in a dose of $50 \mathrm{mg}$ twice a day, 12 hours apart. The pain was assessed at 4,8,12 and 24 hours and was labelled on visual analogue scale where it was rated as 0 as no pain and 10 as maximum possible pain. In cases of pain, rescue analgesia was given in the form of fentanyl boluses in a dose of 25 micrograms.

\section{Statistical analysis}

The data was analyzed by using SPSS version 22.0. The detailed socio demographic and clinical data was collected and mean and standard deviation were assessed by using independent sample $t$ test while frequency and percentages were calculated by using mean Whitney test and Fischer's exact $t$ test for categorical data where the subjects were less than 5 in number. Post stratification $p$ value of $\leq 0.05$ was taken as significant.

\section{Results}

In this study there were 62 cases ( 31 in each group). The mean age in group A and B was $45.41 \pm 10.21$ vs $48.12 \pm 11.13$ years with $p=0.47$. Mean duration of surgery in both groups was $57.51 \pm 15.23$ vs53.11 \pm 14.79 minutes with $\mathrm{p}=0.81$ as shown in table 1 . There were $19(61.29 \%)$ cases from rural population in group A and 22 (70.97\%) in group B (table 2). There was no significant difference in mean pain score at 4 and 8 hours with $p=0.91$ and 0.81 respectively in group $A$ and $B$. Mean pain score was $4.43 \pm 1.67$ vs $3.21 \pm 1.09$ with $p=0.01$ at 12 and $4.57 \pm 1.71$ vs $3.34 \pm 1.27$ at 24 hours in group $A$ and $B$ with $p$ values of 0.01 each as in table 03. Mean time taken for rescue analgesia was $9.13 \pm 2.11$ in group A and 13.11 \pm 1.23 hours in group $B$ with $p=0.001$ (table 4). Mean rescue analgesia used in group A and B was $65.13 \pm 18.67$ vs $87.67 \pm 25.49$ microgram with $p=0.01$ as in table 04 .

Table 1: Demographic comparison of both groups $(n=$ 31 in each group)

Group A Group B p

Age (years) $\quad 45.41 \pm 10.21 \quad 48.12 \pm 11.13 \quad 0.47$

Weight $(\mathrm{kg}) \quad 53.31 \pm 18.05 \quad 57.13 \pm 19.61 \quad 0.78$

$\begin{array}{llll}\text { Duration of surgery (mints) } & 57.51 \pm 15.23 & 53.11 \pm 14.79 & 0.81\end{array}$

Table 2: Categorical demographics ( $n=31$ in each group)

\begin{tabular}{lccc}
\hline & Group A & Group B & p \\
\hline Married & $28(90.32 \%)$ & $27(87.10 \%)$ & 0.95 \\
Unmarried & $3(9.68 \%)$ & $4(12.90 \%)$ & \\
Rural & $19(61.29 \%)$ & $22(70.97 \%)$ & \\
Urban & $12(38.71 \%)$ & $9(29.03 \%)$ & 0.83 \\
Educated & $14(45.16 \%)$ & $12(38.71 \%)$ & \\
Uneducated & $17(54.84 \%)$ & $19(61.29 \%)$ & 0.88 \\
\hline
\end{tabular}


Table 3: Comparison of pain in both groups $(n=31$ in each group)

\begin{tabular}{cccc}
\hline Pain at & Group A & Group B & p \\
\hline 4 hours & $3.17 \pm 1.01$ & $3.11 \pm 1.13$ & 0.91 \\
8 hours & $3.19 \pm 0.97$ & $3.03 \pm 1.04$ & 0.81 \\
12 hours & $4.43 \pm 1.67$ & $3.21 \pm 1.09$ & 0.01 \\
24 hours & $4.57 \pm 1.71$ & $3.34 \pm 1.27$ & 0.01 \\
\hline
\end{tabular}

Table 4: Comparison of need for rescue analgesia in both groups ( $n=31$ in each group)

\begin{tabular}{lccc}
\hline & Group A & Group B & p \\
\hline $\begin{array}{l}\text { Time for rescue } \\
\text { analgesia (hours) }\end{array}$ & $9.13 \pm 2.11$ & $13.11 \pm 1.23$ & 0.001 \\
$\begin{array}{l}\text { Mean dose of rescue } \\
\text { analgesia }\end{array}$ & $65.13 \pm 18.67$ & $87.67 \pm 25.49$ & 0.01 \\
\hline
\end{tabular}

\section{Discussion}

Post operative analgesia is one of the salient entities in post operative care units especially in gynaecological surgeries and better for early mobilization to prevent the risk of deep venous thrombosis. A number of drugs as single or in combination and via various administration routes have been practiced. Per rectal diclofenac and intravenous paracetamol has shown good results individually but lacked one to one data comparison. ${ }^{9-10}$ In this study, there was no significant difference in mean pain score at 4 and 8 hours with $p=0.91$ and 0.81 respectively in group A and B. Mean pain score was $4.43 \pm 1.67$ vs $3.21 \pm 1.09$ with $p=0.01$ at 12 and $4.57 \pm$ 1.71 vs $3.34 \pm 1.27$ at 24 hours in group $A$ and $B$ with $p$ values of 0.01 each. There was limited but variable data in comparison of both of these drugs.

According to a study done by Abraham A et al they also found diclofenac as better agent and it was seen that mean pain score at the end of day 1 ( 24 hours) in diclofenac group was $6.21 \pm 1.24$ as compared to $6.98 \pm$ 1.07 with paracetamol with $p=0.0001$ and they used all the surgeries together along with gynaecological and general surgical procedures. The overall mean pain score in their study was higher than present study but Diclofenac was better agent for pain relief as was seen in our study. ${ }^{11}$

This was also supported by another study done by Taneja et al, where diclofenac was found better than paracetamol in controlling post operative pain in cases of cesarean section with $\mathrm{p}<0.05$. $^{12}$ In a study done by Sede et al they compared combination of diclofenac and paracetamol vs paracetamol alone and it was seen that VAS pain score was significantly lower in combination group compared to other groups all time during first 24 hours $(p<0.05)$ which was almost similar to resent study. ${ }^{13}$ Furthermore, it was found that time for rescue analgesia was $9.13 \pm 2 .^{11}$ in paracetamol group and $13.11 \pm 1.23$ in diclofenac groups; further revealing its efficacy with $\mathrm{p}=0.001$.

However, contradicting results were seen in the study done by Bakhsha F et al where it was seen that in cases undergoing $\mathrm{C}$ section, pain was more in Diclofenac supporsotry group as compared to IV paracetamol and was seen as $5.93 \pm 1.14$ vs $4.53 \pm 1.27$ at 4 hours, $6.4 \pm 1.19$ vs $4.43 \pm 1.17$ at 12 hours and $3.8 \pm 1.13$ vs $3.03 \pm 1.02$ at 24 hours respectively. ${ }^{14}$

\section{Conclusion}

Voltral (Diclofenac sodium) suppositories are better than paracetamol infusion in controlling pain after gynecological surgeries and this difference is significantly better at 12 and 24 hours.

\section{References}

1. Cummings K, Naguib Mohamed A. Stoelting's textbook of pharmacology and physiology in anaesthetic practice: 5 th edition; Opioid agonists and antagonists. 2015:217-241.

2. Weingarten TN, Jacob AK, Njathi CM. Multimodal analgesic protocol and postanesthesia respiratory depression during phase i recovery after total joint arthroplasty. Reg Anesth Pain Med 2015;40:330.

3. Apfelbaum JL, Chen C, Mehta SS, Gan TJ. Postoperative pain experience: result from a national survey suggest postoperative pain continues to be undermanaged. Anesth Analg. 2003;97:534-40.

4. Cousins MJ, Power I, Smith G. Pain_a persistent problem. Reg Analg Pain Med. 2000;25:6-21.

5. Hickman SR, Mathieson KM, Bradford LM, et al. Randomized trial of oral versus intravenous acetaminophen for postoperative pain control. Am J Health Syst Pharm 2018;75:367

6. Jibril F, Sharaby S, Mohamed A, Wilby KJ. Intravenous versus Oral Acetaminophen for Pain: Systematic Review of Current Evidence to Support Clinical Decision-Making. Can J Hosp Pharm 2015;68:238.

7. Paul D, Jacob M, Narayan S. Comparative evaluation of efficacy of intravenous paracetamol and intravenous diclofenac as post-operative analgesia in laparoscopic cholecystectomy. Int J Biomed Research. 2015; 6(7): 482-7.

8. Sarika, Wadhwa R. Research article a randomised double blind study comparing preemptive analgesic efficacy of oral acetaminophen, diclofenac and combination of acetaminophen and diclofenac in modified 
radical mastectomy surgery. Int J Recent Scientific Res. 2015;6(10):6702-6706

9. Ashima T, Vidhushi M, Kaur T. Comparative study on the effect of paracetamol, diclofenac and their combination in post operative pain relief of cesarean section. JK Science. 2015;17(1):30.

10. Luo J, Min S. Post operative pain management in the postanestheisa care unit: an update. Dovepress. 2017; 10:2687-98.

11. Abraham A, James A, George A, Arun J. A comparative study on analgesi effect of paracetamol and diclofenac in post oerpative care. J Res Pharm Sci. 2017; 8(2): 221-26.

12. Taneja A, Kaur T, Sood. Comparative study on the effect of paracetamol, diclofenac and their combination in pot operative pain relief of caesarean section. JH Sci. 2015;17(1):30-2.

13. Sede SS, Tanha FD, Valadan M. Comparison between
Preoperative Rectal Diclofenac Plus Paracetamol and Diclofenac Alone for Postoperative Pain of Hysterectomy. J Family Reprod Health. 2014 Sep; 8(3):91-95.

14. Bakhsha F, Niaki AS, Jafari SY, Yousefi Z. The Effects of Diclofenac Suppository and Intravenous Acetaminophen and their Combination on the Severity of Postoperative Pain in Patients Undergoing Spinal Anaesthesia During Cesarean Section. J Clin Diagn Res. 2016 Jul; 10(7): UC09-UC12.

\section{Authors Contribution}

A.R: Conceptualization of Project

Z.K: Statistical Analysis, Writing of Manuscript

S.R.K: Data Collection

A.M.A.ur.R: Literature Search

U.F, A.N: Drafting, Revision Authors 